\title{
Relationship Between Temperament and Video Game Addiction among Youth
}

\author{
Madiha Asghar ${ }^{1}$ and Maryam Noor \\ Islamia College Peshawar
}

The aim of the present study was to explore the association of temperament and video game addiction among video game addicts and video game non addicts in Peshawar. The total sample consisted of eight hundred and twenty-one $(\mathrm{n}=821)$ youth with the age range of 13 to 18 years, comprising of one hundred and fifty five $(\mathrm{N}=155)$ video game non-addicts and six hundred and seventy-six $(\mathrm{n}=676)$ video game addicts. Convenient sampling and non-probability sampling techniques were used for collecting the data from different schools of Peshawar. The video game addicts were differentiated on the basis of cut off score of 70 and above on the measure of problematic video game addictions test. The study compared video game addicts and non-addicts on the scale of Early Revised Adolescents Questionnaire. The findings of the research indicated that video game addicts face more problems related to personality and temperament than the non-video game addicts. Further findings revealed that video game addicts scored high on elements of aggression and depress mood as compared to video game non-addicts. Further research studies are required to explore the positive outcomes of games and the role of teachers and parents in pushing youth towards these technological games so that primary prevention programs and counseling strategies are offered for the negative consequences of video games.

Keywords: videogame addiction, temperament, aggression, depression and youth

People of all age groups these days are found to be more engaged in playing games on computer especially youth are more eager for playing online and offline games. Video game has become the only leisure

\footnotetext{
${ }^{1}$ Assistant Professor, Department of Psychology, Islamia College Peshawar

${ }^{2}$ Lecturer, Department of Psychology, Islamia College Peshawar
} 
activity for youth of today. Sometimes they engage in this leisure activity without being aware of what they want to achieve with these games.

These electronic games not only affecting their physical health but also have an impact on the personality of youth. These games at times directly and indirectly lead to aggression and temperamental problems in youth which are either not known to the youth or ignored by them and their parents. Findings of the different studies revealed that about 53 and 93 percent of children at elementary school are play computer based games (Amini et al., 2007; Allahwerdi pour et al., 2010). While 15 percent of elementary school children are considered to have developed dependency on video games (Zamani et al., 2009; Allahwerdi pour et al., 2010).

Temperament as is defined by Bates 1989 is the biological attributes of individual's differences in behavioral inclination that are stable and persistent throughout their life. Temperament in the present study is defined through the subscales of Early Adolescents Temperament Questionnaire. The questionnaire consists of following dimensions of temperament and these include activation control, attention, affiliation, inhibitory control, high intensity pleasure, perceptual sensitivity, fear, frustration, activity level, shyness depression and aggression.

1. Activation control is to perform an action instead of having the ability to avoid it.

2. Affiliation is to build close relation with others that is independent of extroversion and shyness.

3. Attention is to be closely attentive to the stimuli and change the attention span when required.

4. Fear is the uneasy feelings in the anticipation of threat.

5. Frustration is the disturb emotions when the person experienced blockage in goal achievement.

6. High intensity pleasure is the pleasurable feelings associated with novelty and high intensity. Inhibitory control is the tendency to avoid and control inappropriate actions.

7. Shyness is the capacity to inhibit social needs, novelty and challenging activities.

8. Aggression is the physical outbursts and the hostile feelings towards others and self that could be direct and indirect.

9. Perceptual sensitivity is the alertness towards low stimulating stimuli in environment.

10. Activity level is the tendency to being active in physical tasks.

PESHAWAR JOURNAL OF PSYCHOLOGY AND BEHAVIORAL SCIENCES, 2016, VOL. 2, NO. 2, 285- 298 
RELATIONSHIP BETWEEN TEMPERAMENT AND VIDEO GAME ADDICTION AMONG YOUTH 287

11. Depressed mood is the disturbance of mood that make person unable to take part in enjoyable activities.

The phenomenon of aggression with adolescents is a focus of attention for many studies. Therefore a number of studies have been conducted to see the relationship of aggression and addiction to video game. Aggression can be a causal factor for many other problems and it can affect life of children in isolation and in combination of many other factors.

The relationship of aggression and video game addiction is of major concern for parents and for school administration and also for the individual itself. Many studies found that aggression is the major consequence of computer based games (Lemmens, Valkenburg, \& Peter, 2011). In another cross sectional design study, it was showed that aggression and delinquent behavior is more related to online video game play (Holtz \& Appel, 2011). Game addiction became a serious social issue and it puts the people at risk for developing problems of irritability and aggression (Park \& Ahn, 2010).

According to different studies sensation seeking is one of the cause of different behaviors like aggression, skydiving, sex, bungee jumping, hiking and camping, body-contact sports or computer and video game playing (Donohew, Lorch, \& Palmgreen, 1991; Palmgreen et al., 1995; Zuckerman, 1979 1994). An adolescent is the period of experimentation with rules, roles and relationship. Jessor and Jessor (1977) suggest that Adolescents consciously seek to engage in risk taking behaviors. They also suggest that during this period sensation seeking is the base for pleasure and fun seeking behavior. The need to change and stimulation seeking is only possible through social, sensory and thrill seeking behavior.

Similarly researches indicated that video game addiction can be a cause of depression (Zamani, 2008; Mohtasham, et al,. 2010). A study in Singapore in two years which intended to differentiate the risk factors and outcomes of pathological gaming, to find out how long pathological gaming lasts, and whether it is a primary problem or a symptom of comorbid problem D. A. Gentile et al. (2011). According to this study, $84 \%$ of children or adolescents who were pathological gamers at the initial stage remained pathological gamers two years later. For children and adolescents who were not pathological gamers in Wave 1 but became pathological gamers in waves 2 or 3 , impulsivity, lower social 
competence and poor emotional regulation skills were the predictors for this change.

D. A. Gentile et al. (2011) also claimed that, although the time spent on gaming was not sufficient to define pathological gaming, several other variables related to the amount of gaming clearly differentiated two groups of individuals. Authors also found that increases in pathological gaming in turn predicted higher levels of depression, anxiety and social phobia, and lower grades. (D. A. Gentile et al., 2011). This was the first study demonstrating that gaming predicts other mental health disorders longitudinally rather than simply correlates with them.

Similarly, very little is known about socioeconomic determinants of problem use, such as education, employment status, and neighborhood characteristics. As one study demonstrated, metabolic changes (including systolic blood pressure and heart rate) resulting from playing the controversially violent game Grand Theft Auto were significantly greater for individuals with exposure to violence in their homes and communities (Brady and Matthews 2006), indicating that complex ecological dimensions of socioeconomic status likely play important roles in how individuals experience distinct game titles or genres.

Different researches find the relationship of different factors with video game addiction. These include educational level of parents, socio economic status, financial status and the availability of internet at home. Different studies in Taiwan (Yen, Yen, Chen, Chen, \& Ko, 2007) and in South Korea M. H. Jang \& Ji, (2012) socioeconomic status was not found to be related to internet addiction.

Demographic variables are found to be closely linked to the problematic use of video games. Recent researches focused the role of age of children and adolescents as a cause for the involvement of video games (Petry, 2011). Few researches were undertaken to examine the role of socioeconomic factors like education status, employment and neighborhood characteristics.

Personal characteristic on the basis of which individual engage in computer games and dependency on these games include neuroticism (Mehroof and Grifiths, 2010), sensation seeking Lin and Tsai, (2002), trait anxiety (Rehbain et al., 2010), low self-esteem Colwell and Payne, (2000) and depression (NG and Weimer- Hastings, 2005).

The factor of gender is also studied by different researchers with regard to video game study (Amini, 2007; Grifiths and Hant, 1995; Lucas and Shry, 2004; Cho and Tsaei, 2007; Genitey, 2008). In one of the study 
RELATIONSHIP BETWEEN TEMPERAMENT AND VIDEO GAME ADDICTION AMONG YOUTH 289

boys were found to be more engaged in computer games for longer time then girls (Cho and Tsai, 2007; Griffiths and Hant, 1995; Griffiths, 1997; Amini et al., 2007). Hug and Jentil (2003) reported those boys who spend more time on these electronic games are significantly addicted to computer games more as compared to girls.

\section{Objectives}

1. To explore the relationship between temperament and video game addiction among video game addicts and video game non-addicts.

2. To find the relationship between temperament and video game addiction among adolescents on different demographics.

3. To ascertain the gender difference in temperament and video game addiction among adolescents.

\section{Hypotheses}

1. Video game addicts will score higher on temperament problems as compared to non- videogame addict.

2. There will be positive relation between temperament problems and videogame addiction.

3. Boys will be more prone to video game addiction as compared to girls.

\section{Results}

Table 1

Temperament; A Predictor of Video Game Addiction

\begin{tabular}{|c|c|c|c|c|c|c|}
\hline \multirow[b]{2}{*}{ Variables } & \multicolumn{3}{|c|}{$\frac{\text { Video Game Non-Addicts }}{(\mathrm{n}=155)}$} & \multicolumn{2}{|c|}{$\frac{\text { Video Game Addicts }}{(\mathrm{n}=676)}$} & \multirow[b]{2}{*}{ B } \\
\hline & $\beta$ & SE & B & $\beta$ & SE & \\
\hline Constant & 35.17 & 3.96 & & 49.59 & $3.60 * *$ & \\
\hline $\mathrm{AC}$ & -.006 & .11 & -.00 & -.32 & $.11^{* *}$ & -.10 \\
\hline Affiliation & .11 & .14 & .07 & .04 & .12 & .01 \\
\hline Attention & .08 & .14 & .05 & -.02 & .11 & -.008 \\
\hline Fear & .09 & .11 & .08 & .01 & .10 & .006 \\
\hline Frustration & -.09 & .09 & -.10 & .09 & .09 & .05 \\
\hline HIP & .00 & .13 & .00 & .12 & .10 & .05 \\
\hline IC & -.37 & .13 & -.25 & -.20 & .12 & -.06 \\
\hline PS & .02 & .13 & .01 & -.13 & .12 & -.05 \\
\hline
\end{tabular}

PESHAWAR JOURNAL OF PSYCHOLOGY AND BEHAVIORAL SCIENCES, 2016, VOL. 2, NO. 2, 285- 298 


\begin{tabular}{|c|c|c|c|c|c|c|}
\hline 90 & & & & & ASGH & ND NOOR \\
\hline Per.S & -.05 & .15 & -.03 & .14 & .13 & .04 \\
\hline Shyness & -.12 & .13 & -.08 & .06 & .11 & .02 \\
\hline $\begin{array}{l}\text { Aggressio } \\
\mathrm{n}\end{array}$ & .20 & .09 & .19 & .47 & $.09 * * *$ & .20 \\
\hline DM & -.09 & .10 & -.08 & .03 & .10 & .01 \\
\hline
\end{tabular}

Table 1 shows temperament as a predictor of video game addiction among video game non-addicts and addicts. The result reveals significant regression equation between activation control and aggression and video game addiction $\mathrm{F}(12,662), 5.014$; the table is statistically significant at $\mathrm{p}<.01$ and .001 respectively. The model explains $8 \%$ of variance with $\mathrm{R}^{2}$ of .08 . So, activation control and aggression is a strong predictor of video game addiction

Table 2

Mean Difference, SD, t-Value of on Temperament on the Basis of Video Game Addiction $(N=821)$

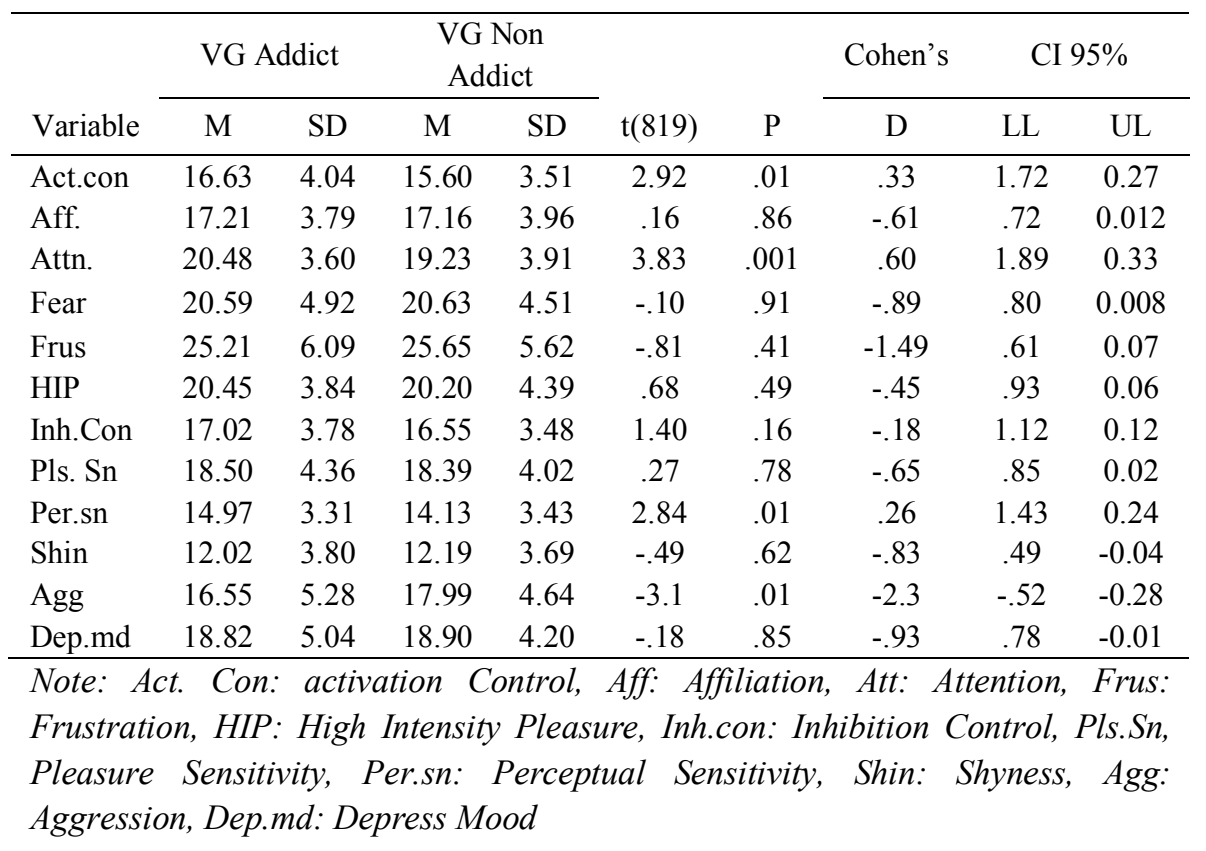

PESHAWAR JOURNAL OF PSYCHOLOGY AND BEHAVIORAL SCIENCES, 2016, VOL. 2, NO. 2, 285 - 298 
RELATIONSHIP BETWEEN TEMPERAMENT AND VIDEO GAME ADDICTION AMONG YOUTH 291

Table 2 shows the mean differences between video game nonaddicts and addicts on the scale of temperament. The table shows that video game addicts shows slightly lower mean as compared to video game non-addicts on activation control, attention, perceptual sensitivity and aggression. This mean difference of overall scores is statistically significant. The results indicate that there is a significant difference between video game non-addicts and video game addicts, so aggression is found high in video game addicts

Table 3

Logistic Regression Analysis of Subscales of Temperament among Video Game Non-addicts and Addicts $(N=821)$

\begin{tabular}{|c|c|c|c|c|}
\hline \multirow[b]{2}{*}{ Variables } & \multirow[b]{2}{*}{$\mathrm{B}(\mathrm{SE})$} & \multicolumn{3}{|c|}{$95 \%$ CI for Odds Ratio } \\
\hline & & Lower & Odds Ratio & Upper \\
\hline Act.con & $-.06(.02)^{*}$ & .89 & .93 & .99 \\
\hline Affiliation & $.01(.02)$ & .95 & 1.01 & 1.07 \\
\hline Attention & $-.07(.02)^{* *}$ & .88 & .92 & .97 \\
\hline Fear & $-.01(.02)$ & .94 & .98 & 1.03 \\
\hline Frustration & $.03(.02)$ & .99 & 1.03 & 1.07 \\
\hline HIP & $.007(.02)$ & .96 & 1.007 & 1.05 \\
\hline Inh.con & $.001(.02)$ & .94 & 1.001 & 1.05 \\
\hline Pls.sen & $.02(.02)$ & .96 & 1.02 & 1.05 \\
\hline Per.sen & $-.09(.03)^{* *}$ & .85 & .91 & .97 \\
\hline Shin & $.001(.02)$ & .95 & 1.001 & 1.05 \\
\hline Aggression & $-.06(.02)^{* *}$ & 1.02 & 1.06 & 1.11 \\
\hline Depressed mood & $-.01(.02)$ & .94 & .98 & 1.03 \\
\hline Constant & $3.04(.80)^{* * *}$ & & 21.03 & \\
\hline \multicolumn{5}{|c|}{$\begin{array}{l}\text { Note: } R^{2}=.049\left(\text { Cox \& Snell), } R^{2}=.080 \text { (Nagelkerke). Model Chi-Sq. }(d f=8) \text {, }\right. \\
3.349, p \text { value }=.911 . *=p<.05, * *=p<.01 \& * * *=p<.001 . C I=\text { Class } \\
\text { Intervals. act. Con: activation Control, Aff: Affiliation, Att: Attention, Frus: } \\
\text { Frustration, HIP: High Intensity Pleasure, Inh.con: Inhibition Control, Pls.Sn, } \\
\text { Pleasure Sensitivity, Per.sn: Perceptual Sensitivity, Shin: Shyness, Agg: } \\
\text { Aggression, Dep.md: Depress Mood }\end{array}$} \\
\hline
\end{tabular}

Table 3 shows logistic regression analysis of temperament as a predictor of video game addiction among video game non-addicts and addicts. A test of the full model against a constant three predictors were statistically significant (chi square 3.349, p>.05, df=8). The Walden criterion demonstrate that made a significant contribution to the prediction 
$(\mathrm{p}<.001)$. Exp (B) value indicated that as the predictor increases the odds of the outcome also increase.

Table 4

Multiple Regression Analysis Predicting Temperament for Video Game Addiction on the Basis of Gender Among Video Game Addicts $(N=821)$

\begin{tabular}{lcccccc}
\hline & \multicolumn{3}{c}{ Boys $(\mathrm{n}=491)$} & & \multicolumn{3}{c}{ Girls(n=182) } \\
Variables & $\mathrm{B}$ & $\mathrm{SE}$ & $\mathrm{B}$ & $\mathrm{B}$ & $\mathrm{SE}$ & $\beta$ \\
\hline Constant & 53.78 & $4.19^{* * *}$ & & 39.14 & $7.26^{* *}$ & \\
AC & -.25 & .14 & -.08 & -.60 & $.20^{*}$ & -.20 \\
Affiliation & -.10 & .15 & -.03 & .22 & .20 & .09 \\
Attention & -.06 & .13 & -.02 & -.02 & .19 & -.009 \\
Fear & -.005 & .13 & -.002 & .06 & .16 & .02 \\
Frustration & .14 & .12 & .07 & -.01 & .15 & -.01 \\
HIP & .22 & .12 & .09 & -.07 & .21 & -.02 \\
IC & -.32 & $.16^{*}$ & -.10 & .02 & .20 & .007 \\
PS & -.09 & .14 & -.03 & -.13 & .21 & -.05 \\
Per.S & .06 & .17 & .02 & .28 & .22 & .10 \\
Shyness & .12 & .14 & .04 & .07 & .21 & .02 \\
Aggression & .45 & $.11^{* * *}$ & .19 & .53 & $.15^{* *}$ & .24 \\
DM & -.08 & .12 & -.03 & .50 & .18 & .21 \\
\hline
\end{tabular}

Note: Act. Con: activation Control, Aff: Affiliation, Att: Attention, Frus: Frustration, HIP: High Intensity Pleasure, Inh.con: Inhibition Control, Pls.Sn, Pleasure Sensitivity, Per.sn: Perceptual Sensitivity, Shin: Shyness, Agg: Aggression, Dep.md: Depress Mood

Table 4 shows temperament as a predictor of video game addiction on the basis of gender among videogame addicts. The result reveals significant regression equation between activation control and aggression and video game addiction. The table is statistically significant at $\mathrm{p}<.01$ and $\mathrm{p}<.001$ respectively. Boys shows high significant relationship between aggression and videogame addiction at $\mathrm{p}<.001$, however the relation between scores on videogame addiction scale and aggression was significant at $\mathrm{p}<.01$ level among girls addicted to videogame playing. 
RELATIONSHIP BETWEEN TEMPERAMENT AND VIDEO GAME ADDICTION AMONG YOUTH 293

Table 5

Multiple Regression Analysis Predicting Temperament for Video Game Addiction on the Basis of Gender Among Video Game Non-Addicts $(N=821)$

\begin{tabular}{|c|c|c|c|c|c|c|}
\hline \multirow[b]{2}{*}{ Variables } & \multicolumn{3}{|c|}{ Boys $(n=77)$} & \multicolumn{3}{|c|}{ Girls $(n=76)$} \\
\hline & $\mathrm{B}$ & SE & $\beta$ & B & SE & $\beta$ \\
\hline Constant & 30.10 & $6.14 * * *$ & & 43.71 & $5.46^{* * *}$ & \\
\hline $\mathrm{AC}$ & .16 & .18 & .12 & -.36 & $.15^{*}$ & -.26 \\
\hline Affiliation & .06 & .22 & .04 & .02 & .20 & .01 \\
\hline Attention & .41 & .24 & .26 & -.37 & .18 & -.25 \\
\hline Fear & -.14 & .18 & -.13 & .26 & .14 & .23 \\
\hline Frustration & -.10 & .15 & -.11 & -.15 & .13 & -.18 \\
\hline HIP & -.09 & .21 & -.06 & .16 & .18 & .11 \\
\hline IC & -.52 & $.22 *$ & -.34 & -.14 & .17 & -.10 \\
\hline PS & .19 & .19 & .14 & -.15 & .20 & -.12 \\
\hline Per.S & -.09 & .22 & -.05 & .13 & .23 & .08 \\
\hline Shyness & -.06 & .20 & -.04 & -.21 & .18 & -.14 \\
\hline Aggression & .24 & .13 & .23 & .28 & $.13^{*}$ & .27 \\
\hline DM & .004 & .14 & .004 & -.08 & .17 & -.06 \\
\hline
\end{tabular}

Table 5 shows temperament as a predictor of video game addiction among male and female video game Non- addicts. The result reveals significant regression equation between activation control and aggression and video game addiction F (12,), 1.30; the table is statistically significant at $\mathrm{p}<.01$ and .001 respectively. The model explains $19 \%$ of variance with $\mathrm{R}^{2}$ of .194 So, activation control and aggression is a strong predictor of video game addiction.

\section{Discussion}

Many studies found a significant relation of aggression and the choice for actions oriented games like (e.g., Anderson, 2004; Anderson \& Dill, 2000; Krahe' \& Mo"1ler, 2004) and some of the Meta-analysis by many researchers also proved this (Anderson, 2004; Anderson \& Bushman, 2001; Anderson et al., 2010; Ferguson, 2007; Sherry, 2001). The present study also identified that youth who played excessive amount of video game has score high on the aggressive component of temperament $p<.001$. Linear Regression analysis in the present study also 
prove that frustration can lead to excessive play of computer games in addicts as compare to non-addicts and the results are significant at $p<.001$. Another component within the temperament which is sensation seeking is also studied and the result was consistent with the previous researches that youth with sensation seeking (Slater et al., 2003) and aggressive nature go for violent media content and they most likely prefer violent games while playing on electronic machines (Joireman, Anderson \& Stratman, 2003). This is not clear that children with aggressive nature go for video game or video game play makes them aggressive. Further research on this factor needs to be done. It is concluded those who does not play video games excessively are not prone to the dangerous effects of video game and they are not as aggressive as those who play excessively theses computer based games. Another dimension of temperament within the present study is activation control which yield a significant result for video game addicts that they have type of temperament due to which they can't stop their response in different situations.

Some studies were done for the purpose to identify symptoms of depression and anxiety in children playing computer based games. Chennan Liu, (2014) proved in his study that playing video games for more than 6 hours per day can lead to isolation and ultimately can cause long term consequences of depression. Another study found social isolation as a mediator of depression and game addiction (Christakis et al., 2011). The result of present study is also consistent with the previous studies which indicated that there is a slight significant relationship between depression and video game addiction. A cross national study in China by Asian adolescents indicates that internet if it is used in excessive amount can cause symptoms of depression (Lam \& Peng, 2010). The similar findings were given by another study in Singapore from longitudinal data that moderate level of video game use is related to coping strategies while the pathological use can cause internalizing disorders (Gentile et al., 2010). The present study findings are consistent to some extent with the previous one as the present study found slight significant result $p<.05$. In the same way (Griffiths, 2010) identify increase level of anxiety in undergraduate students who play more electronic games. Although this factor was not studied in the present study.

The present study is also significant in assuming that boys are more addicted for video games than females Hug and Jentil (2003). Although the frequency of girls was low in the present study as compared 
RELATIONSHIP BETWEEN TEMPERAMENT AND VIDEO GAME ADDICTION AMONG YOUTH 295

to boys using videogame these findings are consistent with the findings of other researchers conducted studies on the same issue previously which assume that boys prefer more aggressive content in video games than girls. This is the reason that boys score high on aggressive temperament than the girls.

\section{Conclusion}

Video game playing is an important phenomenon in the present area of research. Its importance is more highlighted after its inclusion in the DSM-5 as a disorder for further study because still studies are needed to identify it as a disorder. The new generation is more eager to engage in theses technological games then other outdoor activities. This research is conducted to find out the relationship of temperament and video game addiction among youth.

The results of current study identify some temperamental differences of video game addicts and non-addicts. Youth with high engagement were more aggressive and have depressive temperament than the youth who were not addicted to video games. It is concluded from the present study that Youth play games for catharsis of their aggressive and depressive symptoms. The present study also concluded that boys are more prone for aggressive temperament than the girls.

\section{References}

Allahverdipour H, Bazargan M, Farhadinasab A, Moeini B, 2010. Correlates of video games playing among adolescents in an Islamic $\begin{array}{lll}\text { country.BMC Public Health, 10:286 } & \end{array}$ http://www.b.Dmedcentral.com/1471-2458/10/286

American Psychiatric Association (2013). Diagnostic and statistical manual of mental disorders (5th ed.). Arlington, VA: American Psychiatric Publishing.

Amini Y, Mandamini D, 2007. Secondary students and com puter games. Iranian psycho logisguarterly. 4, (4)189-198.

Anderson, C. A. (2004). An update on the effects of playing violent video games. Journal of adolescence, 27(1), 113-122.

Anderson, C. A., \& Bushman, B. J. (2001). Effects of violent video games on aggressive behavior, aggressive cognition, aggressive affect, physiological arousal, and prosocial behavior: A meta-analytic

PESHAWAR JOURNAL OF PSYCHOLOGY AND BEHAVIORAL SCIENCES, 2016, VOL. 2, NO. 2, 285- 298 
review of the scientific literature. Psychological science, 12(5), 353359.

Anderson, C. A., \& Dill, K. E. (2000). Video games and aggressive thoughts, feelings, and behavior in the laboratory and in life. Journal of Personality and social Psychology, 78(4), 772.

Anderson, C. A., Shibuya, A., Ihori, N., Swing, E. L., Bushman, B. J., Sakamoto, A., Saleem, M. (2010). Violent video game effects on aggression, empathy, and prosocial behavior in eastern and western countries: a meta-analytic review. Psychological bulletin, 136(2), 151.

Bates,J.E (1989). Concept and measurement of temperament. In G.A. Kohnstamm, J.E. Bates, \& M.K. Rothbart (eds.), Temperament in childhood (pp.3-26). New York: Wiley.

Brady, S. S., \& Matthews, K. A. (2006). Effects of media violence on health-related outcomes among young men. Archives of Pediatric \& Adolescent Medicine, 160(4), 341-347.

Chou C, Tsai MJ, 2007. Gender differences in Taiwan high school students computer game playing. Computers in Human Behavior, $23,812-824$.

Christakis, D. A., Moreno, M. M., Jelenchick, L., Myaing, M. T., \& Zhou, C. (2011). Problematic internet usage in US college students: a pilot study. BMC medicine, 9(1), 1.

Christopher J. Ferguson, Cheryl K. Olson 2012. Friends, Fun, Frustration and Fantasy: child motivation for video game play. Springer Science+ Business Media, LLC.

Colwell J, Payne J, 2000. Negative correlates of computer game play in adolescents. British Journal of Psychology, 91, 295-310.

Donohew, L., Lorch, E., \& Palmgreen, P. (1991). Sensation seeking and targeting of televised anti-drug PSAs. Persuasive communication and drug abuse prevention, 209-226.

Ferguson, C. J. (2007). Evidence for publication bias in video game violence effects literature: A meta-analytic review. Aggression and Violent behavior, 12(4), 470-482.

Gentile, D. A., Choo, H., Liau, A., Sim, T., Li, D., Fung, D., \& Khoo, A. (2011). Pathological video game use among youths: a two-year longitudinal study. Pediatrics, peds. 2010-1353.

Gentile, D. A., Choo, H., Liau, A., Sim, T., Li, D., Fung, D., et al., (2010). Pathological video game use among youths: A two-year longitudinal study. Pediatrics, 127(2), e319-329. 
RELATIONSHIP BETWEEN TEMPERAMENT AND VIDEO GAME ADDICTION AMONG YOUTH 297

Griffiths MD, Hunt N, 1995. Computer game playing in adolescence: prevalence and demographic indicators. Journal of Community and Applied Social Psychology, 5, 189-193.

Griffiths, M. D. (2010). The role of context in online gaming excess and addiction: Some case study evidence. International Journal of Mental Health and Addiction, 8(1), 119-125.

Holtz, P., \& Appel, M. (2011). Internet use and video gaming predict problem behavior in early adolescence. Journal of Adolescence, 34, 49-58.

Jang, M. H., \& Ji, E. S. (2012). Gender differences in associations between parental problem drinking and early adolescents' internet addiction. Journal for Specialists in Pediatric Nursing, 17, 288-300.

Jessor, R., \& Jessor, S. L. (1977). Problem behavior and psychosocial development: A longitudinal study of youth.

Joireman, J., Anderson, J., \& Strathman, A. (2003). The aggression paradox: understanding links among aggression, sensation seeking, and the consideration of future consequences. Journal of Personality and social Psychology, 84(6), 1287.

Krahé, B., \& Möller, I. (2004). Playing violent electronic games, hostile attributional style, and aggression-related norms in German adolescents. Journal of adolescence, 27(1), 53-69.

Lam, L. T., \& Peng, Z.-W. (2010). Effect of pathological use of the internet on adolescent mental health: a prospective study. Archives of pediatrics \& adolescent medicine, 164(10), 901-906.

Lemmens, J. S., Valkenburg, P. M., \& Peter, J. (2011). The effects of pathological gaming on aggressive behavior. Journal of Youth and Adolescence, 40, 38-47.

Mehroof M, Griffiths MD, 2010. Online gaming addiction: The role of sensation seeking, self-control, neuroticism, aggression, state anxiety, and trait anxiety. Cyber Psychology, Behavior, and Social Networking, 13, 313-316.

Ng, B. D., \& Wiemer-Hastings, P. (2005). Addiction to the internet and online gaming. Cyber Psychology \& Behavior, 8(2), 110-113.

Palmgreen, P., Lorch, E. P., Donohew, L., Harrington, N. G., Dsilva, M., \& Helm, D. (1995). Reaching at-risk populations in a mass media drug abuse prevention campaign: Sensation seeking as a targeting variable. Drugs \& Society, 8(3-4), 29-45.

Park, B.-W., \&Ahn, J.-H.(2010). Policy analysis for online game addiction problems. System Dynamics Review, 26, 117-138.

PESHAWAR JOURNAL OF PSYCHOLOGY AND BEHAVIORAL SCIENCES, 2016, VOL. 2, NO. 2, 285- 298 
Petry, N. M. (2011). Commentary on van rooij et al. (2011): 'Gaming addiction' - a psychiatric disorder or not? Addiction, 106(1), 213214.

Rehbein, F., Psych, G., Kleimann, M., Mediasci, G., \& Thomas. (2010). Prevalence and risk factors of video game dependency in Adolescence: results of a German Nationwide survey. Cyberpsychology, Behavior, and Social Networking, 13(3), 269277.

Sherry, J. L. (2001). The effects of violent video games on aggression. Human communication research, 27(3), 409-431.

Slater, M. D., Henry, K. L., Swaim, R. C., \& Anderson, L. L. (2003). Violent media content and aggressiveness in adolescents a downward spiral model. Communication Research, 30(6), 713-736.

Yen, J.-Y., Yen, C.-F., Chen, C.-C., Chen, S.-H., \&Ko, C.-H. (2007). Family factors of internet addiction and substance use experience in Taiwanese adolescents. Cyberpsychology \& Behavior, 10(3), 323329.

Zuckerman, M. (1979). Sensation seeking: Beyond the optimal level of arousal: Halsted Press.

Zuckerman, M. (1994). Behavioral expressions and biosocial bases of sensation seeking: Cambridge university press. 